\title{
Towards the effectiveness of communication in adopting virtual team for software development
}

\author{
Abdool Qaiyum Mohabuth ${ }^{1}$, Bibi Neehad Nankoo ${ }^{2}$ \\ ${ }^{1}$ University of Mauritius, Faculty of Information Communication \& Digital Technologies, Reduit, Mauritius \\ ${ }^{2}$ Accenture, Ebene, Mauritius \\ a.mohabuth@uom.ac.mu
}

\begin{abstract}
Advancement in technology particularly the development of smart application has caused a paradigm shift in software development. Teams for developing software do not need to be physically present at all times. Members of development teams may be at remote sites but still communicate with each other. Technology has enabled the creation of virtual teams. While technology put at the disposal of software development teams a range of devices for supporting their communication interaction, members still face many challenges in terms of time difference, language barriers and cultural diversification. Ineffective communication among team members lead to delays in software development and contribute much to make project failures. The primary focus of this research is to identify how communication in virtual teams may become efficient. A survey is carried to assess the factors which affect communication in virtual teams. Different team sizes are considered and their relevance and differences in communication interaction are studied. More in-depth data are extracted for this research by interviewing potential members of virtual teams who work and interact from remote sites. The factors which influence communication interaction is finally established which help in successfully managing virtual team projects.
\end{abstract}

Keywords: virtual communication, language barrier, time difference, cultural diversification, virtual interaction.

\section{Introduction}

The ongoing evolution in technology and globalization have influenced the way organisations works today. It is a fact that teams can now work globally at the same time without being under one roof or even meeting each other face-to-face on a daily basis. Software development being a complex activity requires a group of individuals to work effectively as a functional team. Today team members collaborate in the implementation of a project while being physically located at more than one site. Coordination of projects are done virtually by the use of advanced technology. The members of the virtual team can be situated in many different cities, states and countries. For e.g. A virtual project may have some team members in Mauritius and some in France, others in Morocco, all working together to create a customised software on SAP system. Being physically parted from each other, virtual team members depend mainly on technological devices for communicating and exchanging of information [1]. Difference in distance, time and organizational boundaries makes virtual project team dependent on communication technologies. Besides, [2] indicated that a virtual project team can be difficult to describe. [3] stated that virtual team's projects are the most difficult to sustain due to the different locations of the team members working on different time zone. Since team members are found all around the world, this permits organizations to hire and hold the best talent possible [4]. Communication among the virtual teams needs to be supported by communicating technologies which include 
problem-solving information exchange, idea generation, clarifications, resolution of conflicts, negotiating and decision making. These communicating technologies help organisations hold virtual teams by eliminating the factors that separate the teams geographically. The element of trust is an important ingredients in establishing effective communication among members in virtual team. Trust cannot be dissociated from appropriate communication [4]. [5] Pointed out that due to geographical dispersion, founding the feeling of trust and belonging, i.e teamness, within global virtual project teams are quite difficult. Unfortunately, this challenge has not been much exploited in previous research. Being geographically dispersed, virtual team members do not have a regular and continuous communication schedule among themselves. This research explores the challenges faced by virtual team members in establishing proper communication interaction. The issues faced by virtual team members are identified and the factors influencing resource management in the virtual environment are extracted and the possible solutions for improving the communication among the team members are derived.

\section{LITERATURE REVIEW}

Various individual with different roles and duties depending on the project can form a project team. The team can consist of Project Manager, Project lead. Technical lead, Developers,Functional and so on. Members from the team can join in and leave from the project throughout project lifetime [6]. People are grouped in project teams to carry out an explicit task and split when the task is accomplished [7]. The virtual team concept has been created as the organizations need to get projects work done quickly while exploiting different expertise of people found in different geographical locations. The team members who work and live in diverse countries are ethnically diverse [8]. Such teams consist of people who are from different sections, organizations, countries and values. Though, the mutual element across these different definitions is the understanding of virtual team members, they live, work and study in different geographical areas and time zones by using info and communication tools [9]. Team members in virtual projects are materially parted from each other and count mainly on technological devices for communication and exchange of information. It is obvious that virtual project teams will have similar problems faced by collocated team still they will have added areas of concern [10]. The physical distance in space, cultural differences, time zone differences and language barriers are known few challenges faced by virtual project team. Different behavioral skills are required for team building on virtual project teams. [11] pointed out three main reasons affecting the global virtual team are lack of faceto-face contact among team members $(46 \%$ of responses), lack of resources (37\%) and thirdly the time zone variations delaying the facility to collaborate (29\%). [12] claimed that for ensuring proper management, the team must have good and strong communicating plan and control among all the project team members. It is obvious that we have communication issues on projects. Time zone differences and cultural diversification affect communication on projects [13]. Through a faceto-face discussion of a research study, a project manager expressed the struggle of communication with distant resources. [14] specified that, there are three communication-related risk issues namely lack of or insufficient communication, technical connectivity problems that deter communication and inadequate knowledge transfer.

\section{ReSEARCh Methodology}

A survey was conducted in this study where the data was collected on the effectiveness of communication in global virtual team. This approach facilitates the measurements of several variables. The survey is separated into three distinct sections and all questions were numbered. The first section gathers general information that the respondents have on communication in global virtual team. The second part comprises of the questions relating to six factors affecting communication in global virtual team, that is, language, time zone differences, culture, process management, emotions \& conflicts and trusts. Respondents had to express their views on each of 
the questions on the six factors using a five point likert scale. The scale questions used a rating scale 1-5 (SD: Strongly Disagree (SD), 2: Disagree (D), 3:Neutral (N), 4: Agree (A), 5: Strongly Agree (SA). The degree by which these six factors were affected were also measured by rating scale 1-5 (1: Not at all, 2: A little, 3: Neutral, 4: Significantly, 5: Very Significantly). Open-ended questions were also provided for enabling respondents to share their experiences and insights about communication problems faced. The third section focuses on descriptive information about respondents which includes gender, age group, educational background, position, nationality and number of work experience. Descriptive statistics are then derived to give details on the relationship studied between the independent variables such as language, trusts, culture and the dependent variable such as age, gender, number of years of experience.

\section{RESULTS AND DISCUSSIONS}

106 practitioners responded to the survey, out of which $52.8 \%$ were female respondents and the data collected was quantified by using the SPSS software. The majority of respondents (46\%) found that communication in general is slightly effective, $24 \%$ of employees reported neutral, while $18 \%$ did not find communication to be effective and $12 \%$ said communication is moderately effective in virtual environment. As regards to face to face communication, $54 \%$ of the employees argued that face to face contact is 'probably not' a threat for effective communication in the virtual team. The survey revealed that employees mostly used email as communication procedure $(35 \%)$, video conferencing amounted to $31 \%$ and traditional telephone call came to $24 \%$. In addition, $48 \%$ of the employees confirmed that language barrier affected communication in virtual team. As regards to the time differences, the longer the time differences, the more these impacted on virtual team communication as indicated in table 1 . This supports the work of [15] where they found communication timeliness to be relevant to the interaction in virtual team. More differences in time zone, limit the employee opportunities to communicate in real-time which impacted negatively on the team to function virtually.

Table 1: Time zone differences

\begin{tabular}{|l|l|l|l|}
\hline Time Difference & Mean & Std Dev & $\begin{array}{l}\text { Std Error } \\
\text { Mean }\end{array}$ \\
\hline 2-3 hours & 2.840 & 1.070 & 0.104 \\
\hline 4-5 hours & 3.934 & 0.842 & 0.082 \\
\hline 6-8 hours & 4.302 & 0.927 & 0.900 \\
\hline More than 8 hours & 4.547 & 0.977 & 0.949 \\
\hline
\end{tabular}

In addition, cultural differences was found to have significant effect in virtual team communication. This was tested by using one sample t-test which resulted in significant value $p=0$ under five parameters as shown in table 2 .

Table 2: Cultural differences

\begin{tabular}{|c|c|c|c|c|}
\hline & \multicolumn{4}{|c|}{ Test value $=3$} \\
\hline Item & $t$-stat & $\begin{array}{l}\text { Sig Level } \\
\text { (2- } \\
\text { tailed) }\end{array}$ & $\begin{array}{l}\text { Mean } \\
\text { Diff }\end{array}$ & $95 \% \mathrm{Cl}$ \\
\hline $\begin{array}{l}\text { Listening, } \\
\text { speaking same } \\
\text { but not same } \\
\text { interpretation }\end{array}$ & 7.873 & 0.000 & 0.651 & .0487 \\
\hline $\begin{array}{l}\text { Inability to read } \\
\text { between lines } \\
\text { and not able to } \\
\text { understand } \\
\text { certain things }\end{array}$ & 8.840 & 0.000 & 0.793 & 0.615 \\
\hline $\begin{array}{l}\text { Interaction } \\
\text { among team } \\
\text { numbers with } \\
\text { geographical } \\
\text { dispersion }\end{array}$ & 5.956 & 0.000 & 0.576 & 0.384 \\
\hline $\begin{array}{l}\text { Time schedule of } \\
\text { handling duties } \\
\text { varies }\end{array}$ & 4.819 & 0.000 & 0.453 & 0.267 \\
\hline $\begin{array}{l}\text { Expressing or } \\
\text { hiding emotions }\end{array}$ & 5.927 & 0.000 & 0.529 & 0.352 \\
\hline
\end{tabular}

Respondents were also asked how far conflicts affect communication in virtual team. With emergence of ambiguity, employees find it more difficult to manage conflicts in virtual team. 
Further it was noted that the mean for teams which do not have the possibility to meet face- to face, have more conflicts 3.085 with a high standard deviation of 0.9474 and standard error mean of 0.0920 . This implies that team which does not have the possibility for face to face meeting (virtual team) leads to more conflicts. Moreover, the mean for teams which do not have the possibility to meet face-to-face was found to have decreased productivity with a mean of 3.208, a standard deviation of 0.8914 with a standard error mean of 0.0866 , which testified the fact that employees significantly confirm that with lack of face to face meeting, productivity decreases in virtual team. Besides, non-acquaintance or nonrespectful behavior can give rise to significant confusion leading to conflict.

Moreover, other factors such as reading between the lines might cause problem to communication. Building a dialogue can also lead to an interruption of the dialogue in some cultures. Different time schedule in some regions and cultures might result in misunderstandings and obstacles to communication in virtual team. In the same line, [16] confirmed that geographical dispersion and cultural diversity can lead to the development of subgroups which can, in turn, obstruct communication and contribute to the creation of the conflicts in virtual team. It is to be noted also that trusts have also been found to affect projects significantly, as trust leads to better work relationships, improves decision making, and enhanced organisational effectiveness. In this study, lack of trusts in a team is found to lead to significant increase in costs for organisation and this decrease the effectiveness of the team. This finding is in accordance with the work of [17] and [18] whereby they summarized that trust leads to better work relationships, also improved decision making and enhanced organizational effectiveness. Lack of trust leads to an additional time and effort monitoring one another, backing up or duplication each other's work and problems of documentation which leads to time wastage.
The findings of [19] also confirmed that the better the team members communicate among themselves, the stronger the bonds among them which ultimately result in higher trust level in project teams.

\section{RESULTS AND DISCUSSIONS}

Virtual team allows organisations to carry out software development projects, yet the challenges remain very pertinent. Language barrier, time zone differences, conflicts, cultural differences and trusts are found to be those elements that affected communication in virtual team. These elements remain crucial for communication to function in virtual teams for smooth running of software development projects. Team members should be more confident and be a good listener in the virtual interaction. Employers should try to promote the use of common language or shared language in terms of common jargon and communication structures; this will in turn reduce the risk of misinterpretation and will facilitate tasks to move forward. The use of more video call and video conferencing should be promoted; this will in turn reduce the number of emails thus reducing the language barrier. In addition, the use of chat platform specific to the team which is accessible through mobile phones should be encouraged. Use of holograms, Skype, google meet, zoom platform etc. could be adopted to enhance communication. Regular chat sessions with all team members should be engaged; this will improve social communication and mitigate the negative effects of cultural differences. More activities that increase cohesiveness should be introduced. Knowledge sharing and taste sharing should be introduced to enhance virtual team spirit. The study was constrained by using explanatory variables and small sample size which affect communication in virtual environment in Mauritius. It needs to be repeated on a larger sample size to capture other potential determinants by including scoring and ranking questions and multiple response questions that might have an impact on communication in the virtual 
environment. This will lead to more enhanced result to improve the virtual environment.

\section{References}

[1] G. D'Souza and S. Colarelli, “Team member selection decisions for virtual versus face-to-face teams," Computers in Human Behavior, XXVI (4), pp. 630-635, 2010.

[2] P. Rad and G. Levin, Achieving Project Management Success Using Virtual Teams, Boca Raton: J. Ross Publishing, Incorporated, 2014.

[3] K. Fisher and M. Fisher, The distance manager: A hands-on guide to managing off-site employees and virtual teams, New York: McGraw-Hill, 2001.

[4] A. Kankanhalli, B. Tan, and K. Wei, "Conflict and Performance in Global Virtual Teams," Journal of Management Information Systems, XXIII (3), pp. 237274, 2006.

[5] O. Stawnicza, "Information and Communication Technologies - Creating Oneness in Globally Distributed IT Project Teams," Procedia Technology, 16, pp. 1057 - 1064, 2014.

[6] H. Holmström, E. Ó Conchúir, P. Ågerfalk, and B. Fitzgerald, "Global Software Development Challenges: A Case Study on Temporal, Geographical and Socio-Cultural Distance," In Proceedings of the International Conference on Global Software Engineering (ICGSE2006), 2006.

[7] R. Mulcahy, PMP exam prep: Accelerated learning to pass PMI's PMP exam on your First try! (5th ed.), Rmc Pubns, 2005.

[8] D. Walker, Global Project Management: Communication, Collaboration and Management Across Borders 20092J, Binder Global Project Management: Communication, Collaboration and Management Across Borders, Aldershot, UK: Gower Publishing Company, 2009.

[9] A. Powell, G. Piccoli, and B. Ives, "Virtual teams: a review of current literature and directions for future research," ACM SIGMIS Database: the DATABASE for Advances in Information Systems, XXXV (1), pp. 6-36, 2004.
[10] R. Huang, S. Kahai, and R. Jestice, "The contingent effects of leadership on team collaboration in virtual teams," Computers in Human Behavior, XXVI (5), pp.10981110, 2010.

[11] C. Aldea, A. Popescu, A. Draghici, and G. Draghici, "ICT Tools Functionalities Analysis for the Decision-Making Process of Their Implementation in Virtual Engineering Teams," Procedia Technology, 5, pp.649-658, 2012.

[12] O. Cristian, C. Cosmina, “ Managing processes for Virtual Teams- a BPM approach," Procedia - Social and Behavioral Sciences, pp. 380 - 384, 2014.

[13] S. Lilian, "Virtual Teams: Opportunities and Challenges for e-Leaders," Procedia Social and Behavioral Sciences, 110, pp. 1251-1261, 2014.

[14] L. Lee-Kelley and T. Sankey, "Global virtual teams for value creation and project success: A case study," International Journal of Project Management, XXVI (1), pp.5162, 2008.

[15] A. Reed and L. Knight, "Effect of a virtual project team environment on communication-related project risk," International Journal of Project Management, XXVIII (5), pp. 422-427, 2010.

[16] S. Marlow, C. Lacerenza, and E. Salas, "Communication in virtual teams: a conceptual framework and research agenda," Human Resource Management Review, XXVII (4), pp. 575-58, 2017.

[17] J. Wildman and R. Griffith, Leading global teams: Translating Multidisciplinary science to practice, United States: Springer-Verlag New York, 2014.

[18] J. Wilson, S. Straus, and B. McEvily, "All in due time: The development of trust in computer-mediated and face-to-face teams," Organizational Behavior and Human Decision Processes, XCIX (1), pp.16-33, 2006.

[19] F. Jeffries and T. Becker, "Trust, norms, and cooperation: Development and test of a simplified model," Journal of Behavioral and Applied Management, IX (3), pp. 316338, 2008. 